\title{
Development of multiwalled carbon nanotubes platinum nanocomposite as efficient PEM fuel cell catalyst
}

\author{
Chanchal Gupta $^{1,2} \cdot$ Priyanka H. Maheshwari ${ }^{1,2} \cdot$ Sanjay R. Dhakate ${ }^{1}$
}

Received: 11 June 2015/Accepted: 20 December 2015/Published online: 14 January 2016

(C) The Author(s) 2016. This article is published with open access at Springerlink.com

\begin{abstract}
Multiwalled carbon nanotubes platinum nanocomposite has been prepared via chemical route by reduction of Pt salt on MWCNTs in ethylene glycol solution while refluxing in Argon atmosphere. The effect of different $\mathrm{pH}$ media during the reduction process on their physical and electrochemical properties, as well as on their performance in unit PEM fuel cell has been studied and further compared with the reaction carried out while refluxing in air as already demonstrated by the authors. The $I-V$ performance of unit PEM fuel cell shows a peak Power density of $156 \mathrm{~mW} \mathrm{~cm}{ }^{-2}$ with catalyst prepared in alkaline medium, an increase of $>110 \%$ as compared to $72 \mathrm{~mW} \mathrm{~cm}{ }^{-2}$ obtained while employing catalyst prepared in acidic medium and tested under similar conditions. This is attributed not only to the small particle size of reduced $\mathrm{Pt}$ NPs, but also to its uniform distribution when reduction is carried out in alkaline medium. This has been further explained by detail reaction mechanism under alkaline conditions.
\end{abstract}

Keywords Carbon nanotubes · Catalyst - Fuel cell · Midwave potential $\cdot$ Polarization

Priyanka H. Maheshwari

hedap@mail.nplindia.ernet.in

1 Physics and Engineering of Carbon, CSIR-National Physical Laboratory, New Delhi, India

2 Academy of Scientific and Innovative Research (AcSIR), CSIR-NPL Campus, New Delhi, India

\section{Introduction}

Among the various types of fuel cells, Polymer Electrolyte Membrane (PEM) fuel cells have attracted most of the researchers because of their advantages like low emissions, low operating temperature and high power density and use of all solid state components, which make them suitable for portable applications [1-4]. Despite various advantages, the sluggish kinetics of ORR (oxygen reduction reaction) is the limiting factor for energy conversion in PEM fuel cells. This necessitates the use of an efficient electro catalyst, wherein Pt or Pt-based alloy catalyst supported on high surface area carbon black is generally used. Due to the amorphous nature of carbon black, it tends to agglomerate and corrode with repeated fuel cell operation. This not only increases the cost of the catalyst, but also leads to insufficient durability [5-9]. Therefore, development of efficient, low cost and highly durable catalyst is the major concern towards the commercialization of fuel cells. In this context, carbon materials like ordered mesoporous carbons (OMCs) [10], carbon aerogels [11], carbon nanotubes (CNTs) [5, 12-15], carbon nano-horns (CNHs) [16], carbon nano-coils (CNCs) [17] and carbon nano fibers (CNFs) [18] have attracted much interest as electro catalyst support. Amongst them CNTs have been considered as the most attractive support material due to its high crystallinity, hydrophobicity, high conductivity, chemical inertness and high surface area [19-24]. These properties not only make them suitable for catalyst support, but they are increasingly being used in other cell components like GDL [25-28], carbon paper [29] and bipolar plates [30]. However, chemically inert nature of CNTs lowers the effective reaction sites for attachment of metal nanoparticles. To overcome this, many efforts have been done to modify the surface of CNTs by chemical functionalization 
[31-33]. The chemical oxidation method introduces the acid functional groups on the surface of CNTs; nevertheless it introduces irreversibly structural defects, which reduces the electrical conductivity and the durability of CNTs [34, 35].Various treatments including sono-chemical [36], electrochemical [37], microwave heating [38] and reflux heating $[39,40]$ have been proposed to incorporate Pt nano particles onto the CNT surface.

In the present study we use pristine CNTs to avoid the surface oxidation process and we demonstrate the development of Pt/CNT by reduction of chloroplatinic acid via refluxing in varying $\mathrm{pH}$ media and in argon environment. The above decision was driven by the thought that

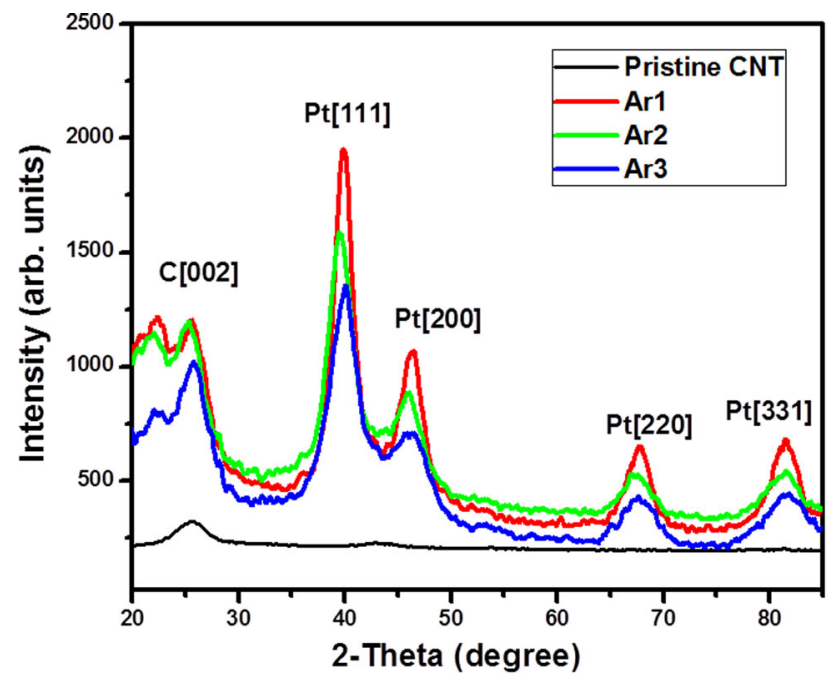

Fig. 1 X-ray diffraction curves of pristine CNTs and sample Ar1, $\operatorname{Ar} 2$, and $\operatorname{Ar} 3$ refluxing in an inert atmosphere, will control the defect formation and lead to a smooth surface, thereby providing identical surface sites, resulting in an enhanced catalytic activity of the nanocomposite formed.

This study gives a detail account of how the varying conditions of $\mathrm{pH}$ during the reduction process affect the properties of the synthesized nanocomposites and their corresponding behavior as catalyst for PEM fuel cell. This in turn is supported by characterizations like TGA, TEM, XRD, Raman spectroscopy, XPS and electrochemical techniques like cyclic voltammetry $(\mathrm{CV})$ and linear sweep voltammetry (LSV) and finally the samples have been tested for their performance in unit PEM fuel cell.

\section{Materials and methods}

\section{Development of Pt/CNT nanocomposite}

Commercially available Nanocyl 7000 MWCNTs with diameter in the range of $20-30 \mathrm{~nm}$ and aspect ratio $>1000$ were used for the preparation of Pt/CNTs. Ethylene glycol and Hexachloroplatic acid $\left(\mathrm{H}_{2} \mathrm{PtCl}_{6} \cdot 6 \mathrm{H}_{2} \mathrm{O}\right)$ were procured from Merc Ltd. and Acros Organics, respectively. Ar gas with $99.9 \%$ purity and double deionized water is used wherever required.

Pristine MWCNTs were uniformly dispersed in ethylene glycol by ultra-sonication for $\sim 3 \mathrm{~h}$. Solution of $0.01 \mathrm{M}$ $\mathrm{H}_{2} \mathrm{PtCl}_{6}$ (chloroplatinic acid) in IPA was added to the above drop by drop under constant magnetic stirring such that the ratio of $\mathrm{Pt}: \mathrm{CNT}$ is $1: 4$. The $\mathrm{pH}$ of the above solution was measured and found to be less than 2. To

Table 1 Miller indices, d-spacing and crystallite size for the given diffraction angle for samples Ar1, Ar2, and Ar3

\begin{tabular}{|c|c|c|c|c|c|c|}
\hline $\begin{array}{l}\text { Sample } \\
\text { name }\end{array}$ & $\begin{array}{l}\text { Miller } \\
\text { indices }\end{array}$ & $\begin{array}{l}\text { Peak position (in } \\
\text { degrees) }\end{array}$ & $\begin{array}{l}\text { d-spacing } \\
(\mathrm{nm})\end{array}$ & $\begin{array}{l}\text { FWHM (in } \\
\text { degrees) }\end{array}$ & $\begin{array}{l}\text { Crystallite size } \\
(\mathrm{nm})\end{array}$ & $\begin{array}{l}\text { Average crystallite size of } \mathrm{Pt} \\
(\mathrm{nm})\end{array}$ \\
\hline \multirow[t]{5}{*}{ Ar1 } & $\mathrm{C}(002)$ & 25.67 & 3.46 & 4.04 & 2.01 & \\
\hline & $\operatorname{Pt}(111)$ & 39.99 & 2.25 & 2.45 & 3.44 & 3.62 \\
\hline & $\operatorname{Pt}(200)$ & 46.06 & 1.96 & 3.56 & 2.43 & \\
\hline & $\operatorname{Pt}(220)$ & 67.88 & 1.38 & 2.28 & 4.22 & \\
\hline & $\operatorname{Pt}(311)$ & 81.70 & 1.17 & 2.39 & 4.39 & \\
\hline \multirow[t]{5}{*}{ Ar2 } & $\mathrm{C}(002)$ & 25.42 & 3.51 & 6.19 & 1.31 & \\
\hline & $\operatorname{Pt}(111)$ & 39.85 & 2.26 & 3.43 & 2.46 & 2.67 \\
\hline & $\operatorname{Pt}(200)$ & 45.96 & 1.97 & 4.15 & 2.07 & \\
\hline & $\operatorname{Pt}(220)$ & 67.57 & 1.38 & 3.47 & 2.75 & \\
\hline & $\operatorname{Pt}(311)$ & 81.21 & 1.18 & 3.06 & 3.41 & \\
\hline \multirow[t]{5}{*}{ Ar3 } & $\mathrm{C}(002)$ & 25.54 & 3.48 & 4.66 & 1.74 & \\
\hline & $\operatorname{Pt}(111)$ & 39.82 & 2.26 & 3.98 & 2.12 & 2.29 \\
\hline & $\operatorname{Pt}(200)$ & 46.24 & 1.96 & 4.32 & 1.99 & \\
\hline & $\operatorname{Pt}(220)$ & 67.67 & 1.38 & 4.23 & 2.25 & \\
\hline & $\operatorname{Pt}(311)$ & 81.92 & 3.74 & 1.18 & 2.81 & \\
\hline
\end{tabular}


make the samples of different $\mathrm{pH}$ (i.e., 2, 7 and 11) $0.1 \mathrm{M}$ $\mathrm{NaOH}$ was added with continuous stirring. This was further refluxed at $140{ }^{\circ} \mathrm{C}$ for $3 \mathrm{~h}$ in argon. This process of reduction, immobilizes $\mathrm{Pt}$ on CNTs forming $\mathrm{Pt} / \mathrm{CNTs}$ nanocomposites. The solution was filtered followed by washing with copious amount of double de-ionized water.

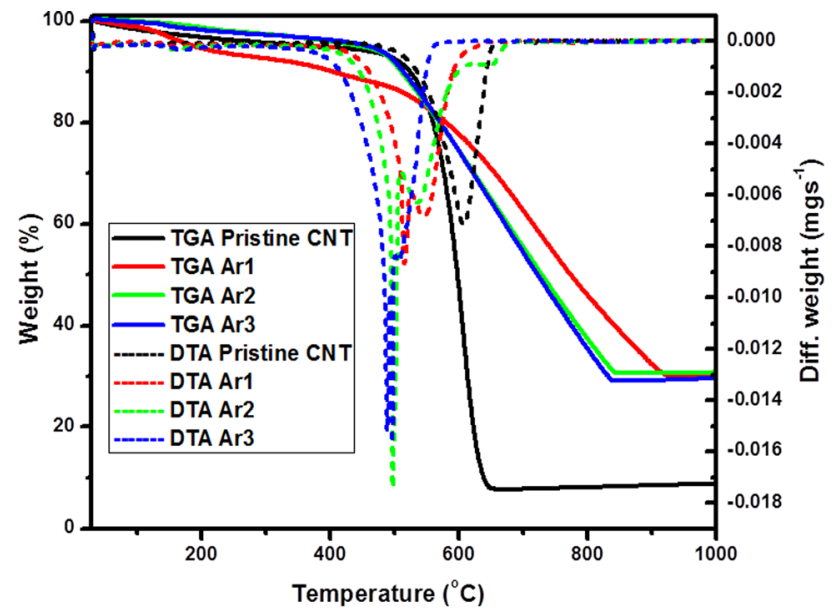

Fig. 2 TGA curves of pristine CNTs and sample Ar1, Ar2, and Ar3
The filtrate was further dried to obtain powdered catalyst. Dilute solution of $\mathrm{NaBH}_{4}$ was added to residue to detect the presence of unreacted platinum. The samples prepared by refluxing the solution in acidic, neutral, and alkaline mediums ( $\mathrm{pH} 2,7$, and 11) in argon have been designated as $\operatorname{Ar} 1, \operatorname{Ar} 2$, and Ar3, respectively.

\section{Physical characterization}

The X-ray diffraction (examination of the samples was performed on Rikagu powder X-ray diffractometer model: XRG $2 \mathrm{KW}$ using $\mathrm{Cu} \mathrm{K} \alpha$ radiation. The mean crystallite size and lattice parameters were calculated from line broadening and d-spacing measurements using the (002) and (100) reflections. Thermal gravimetric analysis of the electrode samples was carried out on TGA/DSC 1600 by Mettler Todedo. The experiments were carried out in air at the rate of $10{ }^{\circ} \mathrm{C} / \mathrm{min}$. The structural details of the MWCNT samples were studied with the help of transmission electron microscopy (TEM) using Tecnai G2 F30 S-Twin instrument. Raman spectroscopy was carried out using a Renishaw InVia Reflex Micro Raman Spectrometer equipped with the CCD detector at room temperature and
Fig. 3 a-c TEM images of Ar3 sample and $\mathbf{d}$ particle size distribution curve for Ar3
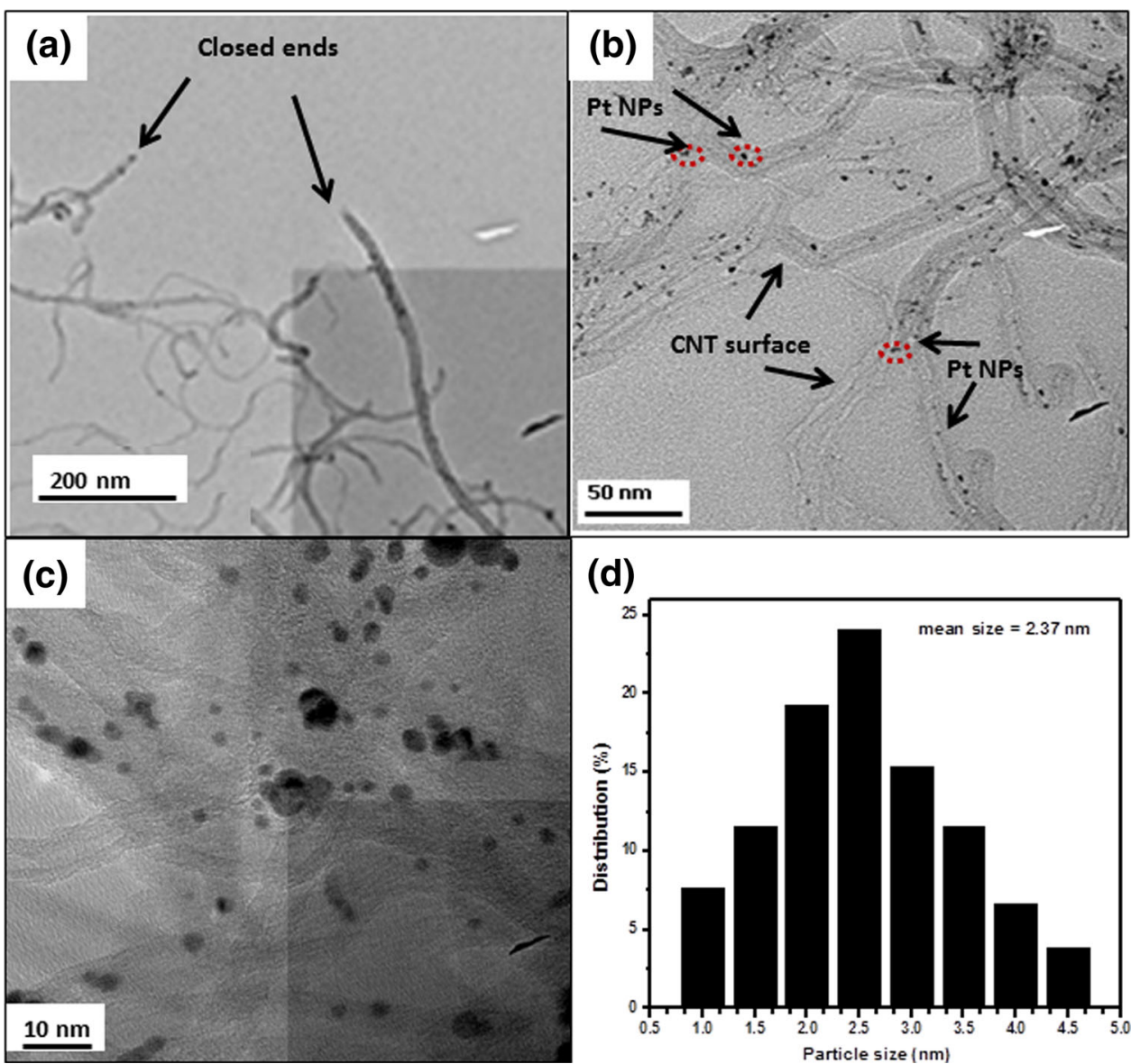

(d)

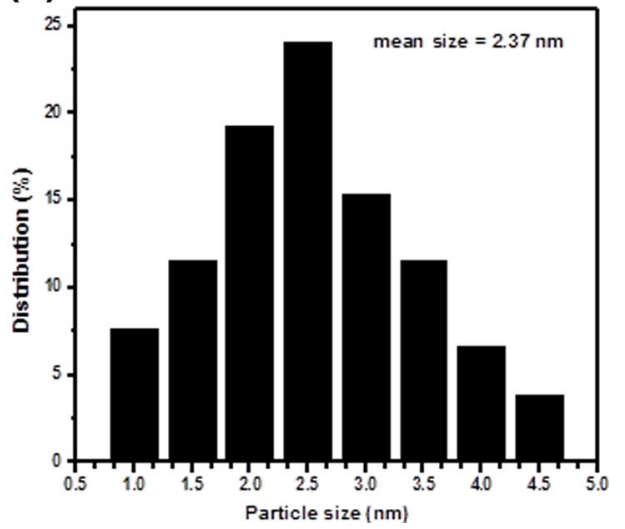



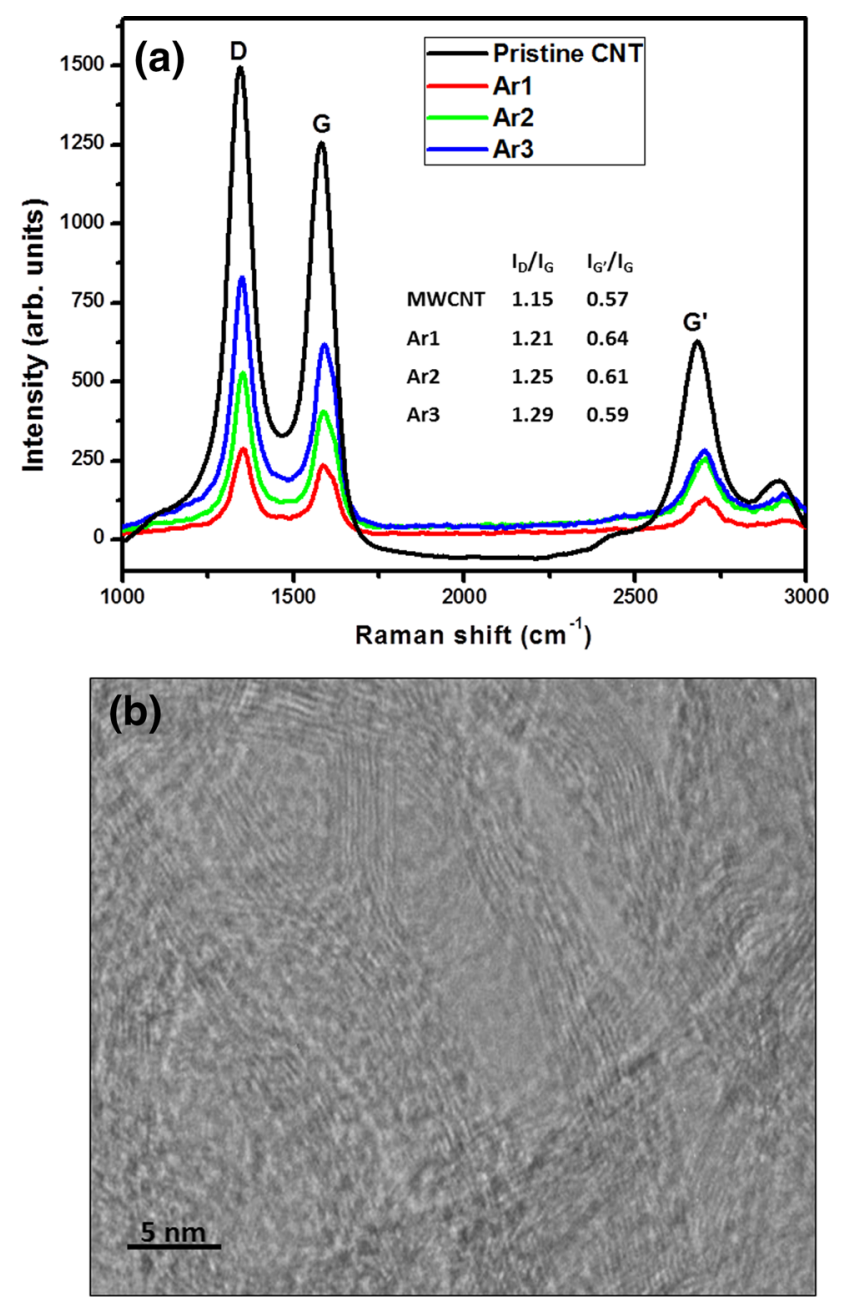

Fig. 4 a Raman spectra of pristine CNTs and sample Ar1, Ar2, and Ar3; b HRTEM image of pristine multiwalled carbon nanotube

in air. Green laser (excitation line $514 \mathrm{~nm}$ ) was used to excite the samples. One scan per sample was recorded wherein the samples were exposed to the laser power of $25 \mathrm{~mW}$ for $10 \mathrm{~s}$.

\section{Electrochemical characterization}

The electrochemical measurements were performed using Biologic instrument (VSP model and EC-Lab software) at $25{ }^{\circ} \mathrm{C}$. Conventional three electrode system was used for $\mathrm{CV}$ measurements saturated calomel electrode (SCE), Pt foil and glassy carbon (GC) as reference electrode, counter electrode and working electrode, respectively. The catalyst ink was prepared by dispersing $4.26 \mathrm{mg}$ of catalyst in $1 \mathrm{ml}$ ethanol. A drop of $5 \%$ nafion solution was then added to the above solution and sonicated for $30 \mathrm{~min}$. The working electrode was prepared by drop casting the catalyst ink on the glassy carbon electrode such the platinum loading is $60 \mu \mathrm{g} / \mathrm{cm}^{2}$. Four electrodes per sample were prepared and tested under similar conditions. The value of ECSA is determined experimentally using cyclic voltammetry in $\mathrm{N}_{2}$ purged $0.5 \mathrm{M} \mathrm{HClO}_{4}$ solution. Kinetic activity for ORR is measured ex situ with Linear scan voltammetry (LSV) in rotating disk electrode (RDE) apparatus with $1600 \mathrm{rpm}$ rotating rate and $5 \mathrm{mVs}^{-1}$ sweep rate in $\mathrm{O}_{2}$ purged $0.5 \mathrm{M}$ $\mathrm{HClO}_{4}$ solution.

For fuel cell performance Toray carbon paper samples of size $25 \mathrm{~cm}^{2}$ were teflonized and gas diffusion layer (GDL) was prepared by coating $1.5 \mathrm{mg} \mathrm{cm}^{-2}$ of carbon black (Vulcan XC-500) by brush coating technique, followed by sintering at $350{ }^{\circ} \mathrm{C}$ for $30 \mathrm{~min}$. The catalyst ink was prepared by mixing the synthesized catalyst with nafion ( $7 \mathrm{wt} \%$ of catalyst). The ink was then brush coated onto the GDL such the amount of catalyst loading is $0.3 \mathrm{mg} \mathrm{cm}^{-2} \mathrm{Pt}$. Nafion Membrane-1135 (DuPont) was sandwiched in between the two electrodes (as prepared above) and hot pressed at $120-130{ }^{\circ} \mathrm{C}$ for $3 \mathrm{~min}$. to make the membrane electrode assembly (MEA). The cells were tested at $60{ }^{\circ} \mathrm{C}$ and $100 \%$ humidified conditions with the flow rate of hydrogen and oxygen gasses maintained at 200 and $300 \mathrm{~mL} \mathrm{~min}^{-1}$, respectively, at atmospheric pressure. Measurements of cell potential with varying current densities were conducted galvanostatically using MODELLCN4-25-24/LCN 50-24 procured from Bitrode Instruments (US).

\section{Results and discussion}

The XRD patterns for Pt/CNTs are shown in Fig. 1. Diffraction peak at $\sim 26^{\circ}$ is attributed to graphite crystallographic planes (002) of CNT. Pt/CNTs show the presence diffraction peaks at nearly $40^{\circ}, 46^{\circ}, 67.5^{\circ}$, and $81^{\circ}$ corresponding to (111), (200), (220) and (311) planes of Platinum, respectively. These are analogous to the facecentered cubic structure of the noble metal. For all diffraction peaks the average crystallite size has been calculated from FWHM (full width at half maximum) values using Debye-Scherrer equation [41]. Table 1 gives a detailed account of the observed diffraction peaks along with their corresponding d-value and FWHM. The crystallite size of platinum has been calculated as an average of that obtained from different peaks. The average crystallite size decreases with increase in the $\mathrm{pH}$ of the refluxing medium. This can be explained as follows. At higher $\mathrm{pH}$ $\mathrm{OH}^{-}$ions are available to replace $\mathrm{Cl}^{-}$in the hexachloro platinic acid since $\mathrm{OH}^{-}$ligand has higher field strength than $\mathrm{Cl}^{-}$in the spectro-chemical series. Further, the Extended X-ray adsorption fine structure studies (EXAFS) confirmed that $\mathrm{Pt}-\mathrm{OH}$ bond is smaller than $\mathrm{Pt}-\mathrm{Cl}$ bond [42, 43]. Hence, due to steric contraction effect the complexes formed in basic medium is smaller than the complexes formed in acidic medium [44]. 

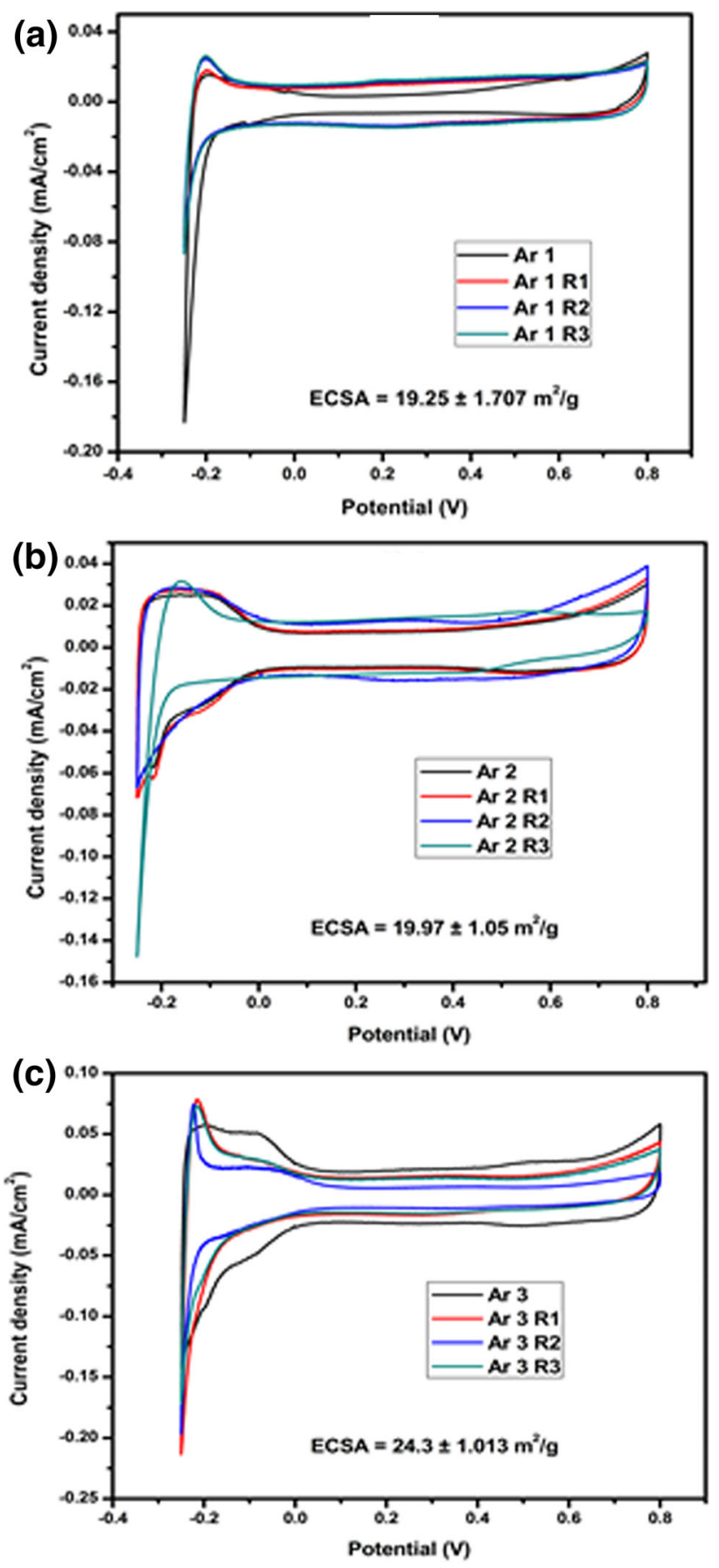

Fig. $5 \mathrm{CV}$ curves of 4 different electrodes prepared for samples a Ar1, b Ar2, and c Ar3 in $\mathrm{N}_{2}$ purged $0.5 \mathrm{M} \mathrm{HClO}_{4}$

Figure 2 shows the TGA and DTG curves of the catalyst samples along with that for the pristine CNTs. TGA for Nanocyl MWCNT without Platinum addition shows a residue about $8.5 \%$ which may be due to the presence of catalyst (metal/oxide) used during the CNT synthesis process. For the Pt/CNTs sample prepared in argon atmosphere with different $\mathrm{pH}$ medium shows the residue of $\sim 29 \%$, which indicates that nearly all of
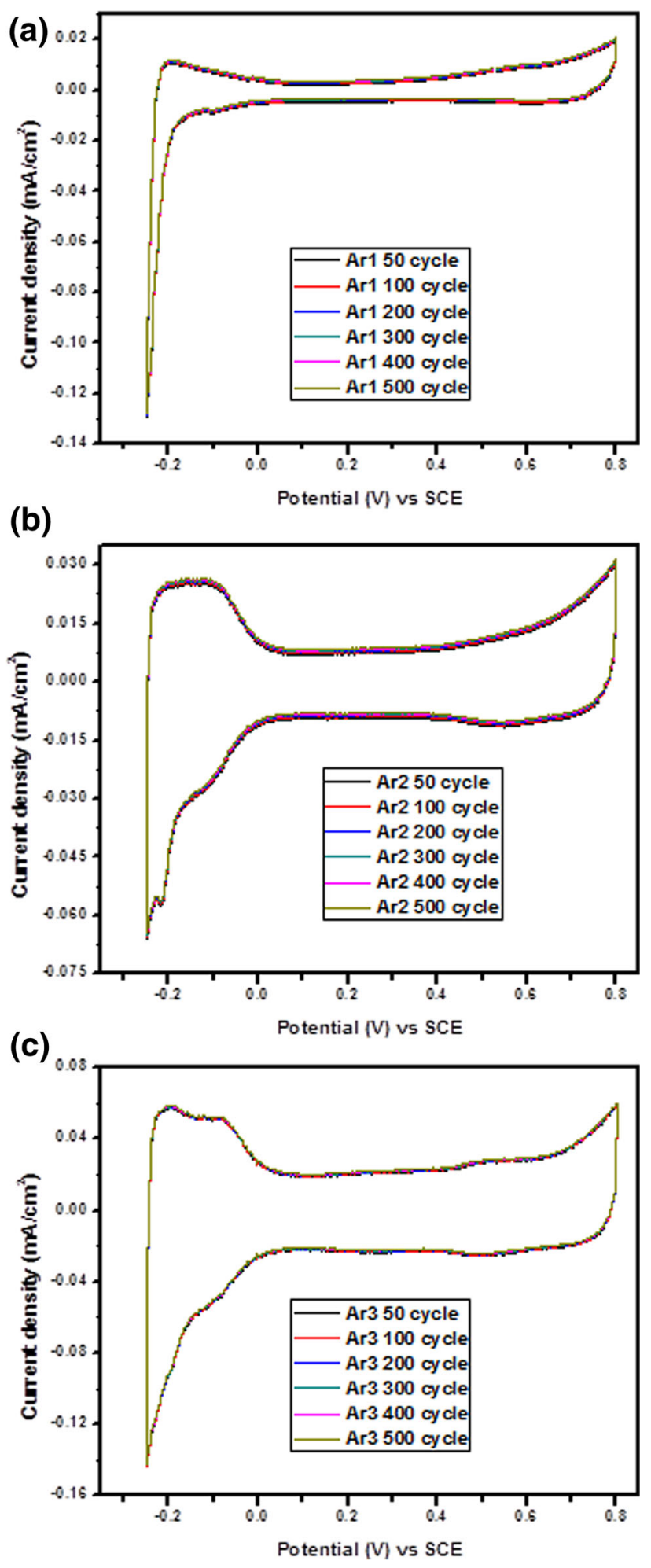

Fig. 6 CV curves of sample a Ar1, b Ar2, and c Ar3 for 500 cycles the platinum (i.e., $20 \%$ ) was reduced on the CNT surface.

As shown by the DTG curves, the thermal stability of the nanocomposites reduces as compared to pristine CNTs. This is because, (1) the metal nanoparticles acts as defects 
and catalyze the oxidation process; and (2) there is a probability that defects are also introduced in the nanotube structure during the refluxing process. These results have been further confirmed by Raman spectroscopy.

TEM micrograph for Pt/CNT nanocomposite in basic medium (Ar3) is shown in Fig. 3 reveals that platinum particles are attached to the outer walls of CNT. Figure 3(a) inset shows the presence of closed ends of CNT this means during synthesis process the CNTs remains highly intact and deposition of platinum particles only occurs at the surface of CNTs. The particle size distribution (PSD) curve has been plotted for Ar3 for average of 500 particles, shows that the mean crystallite size is nearly $2.37 \mathrm{~nm}$ which is in close agreement with the values measured from XRD.

Figure 4a shows the Raman spectra for catalysts samples. The D (defect), G (graphitic) and $\mathrm{G}^{\prime}$ (second-order harmonic to $\mathrm{D}$ ) bands are clearly visible. $\mathrm{D}$ band is related to the defects presents on CNTs, whereas the G band originates from the presence of $\mathrm{sp}^{2}$-hybridized carbon sites present in the sample and hence represents the frequency of carbon-carbon double bond stretching vibration [45]. The $\mathrm{G}^{\prime}$ band is the second-order harmonic to D and represents defect in the stacking sequence. The intensities of the bands were determined by the area under the spectral curve. The intensity of the $\mathrm{G}$ band $\left(I_{\mathrm{G}}\right)$ has been used as a reference in determining the relative intensities of the $D$ band $\left(I_{\mathrm{D}}\right)$ and $\mathrm{G}^{\prime}$ band $\left(I_{\mathrm{G}^{\prime}}\right)$.

For pristine CNTs $I_{\mathrm{D}} / I_{\mathrm{G}}$ ratio is 1.15 which is quite high and indicates the presence of defects. The major contributors to the defects are, (1) the large number of pentagons that are present at the closed ends of the tubes; (2) presence of metal oxides used as catalyst for initiating the growth of CNTs which accounts to nearly $8.7 \%$ of the CNT weight (as shown by the TGA curve); (3) imperfect CNT walls as shown by the high-resolution TEM image (Fig. 4b).

After incorporation of platinum the $I_{\mathrm{D}} / I_{\mathrm{G}}$ value increases which indicated the stresses induce on the hexagonal structure of carbon. A slight increase in the values of $I_{\mathrm{G}^{\prime}} / I_{\mathrm{G}}$ indicated that $\mathrm{Pt}$ incorporation also influences the coupling of few CNT layers.

The CV curves of catalyst samples (Ar1, Ar2, and Ar3) of the four electrodes prepared are shown in Fig. 5a, b, c, respectively, while the curves uptill 500 cycles for one of the electrodes are shown in Fig. 6a, b, c, respectively. The curves exhibit typical characteristic of crystalline Pt electrodes in the hydrogen and oxygen adsorption-desorption regions which illustrates the presence of platinum particles on the carbon surface. The ECSA of the hydrogen desorption peak calculated from the $\mathrm{CV}$ curves gives a measure of the HOR. ECSA has been calculated for all the electrodes prepared for Ar1, Ar2, and Ar3 (as shown in Table 2) and the standard deviation for the four curves of each sample has been calculated. The average value was found to be maximum for sample Ar3. The increase in ECSA is mainly attributed towards the decrease in crystallite size of the $\mathrm{Pt}$ with increase in $\mathrm{pH}$ of the refluxing medium. Importantly, there is no decrease in the current with successive cycling (as shown in Fig. 6), which in turn is the measure of the durability of the sample, as reported elsewhere [46-48].

However, for fuel cells the ORR at cathode side is more critical as it is much slower than the HOR at anode. The LSV curves for the four different electrodes prepared for the Pt/CNT nanocomposites are shown in Fig. 7a, b, c. The curves show a low value of limiting current for all the catalyst samples, probably because of the defects present on the CNTs [as is clear from the high value of $I_{\mathrm{D}} / I_{\mathrm{G}}$

Table 2 ECSA, diffusion limiting current density, onset potential, and mid-wave potential calculated from the CV curves for all the electrodes prepared for samples Ar1, Ar2, and Ar3

\begin{tabular}{|c|c|c|c|c|}
\hline Sample & $\operatorname{ECSA}\left(\mathrm{m}^{2} / \mathrm{g}\right)$ & $\operatorname{DLCD}\left(\mathrm{mA} / \mathrm{cm}^{2}\right)$ & Onset potential (V) & Mid-wave potential (V) \\
\hline \multirow[t]{4}{*}{ Ar1 } & 17 & 0.3866 & 0.7498 & 0.3224 \\
\hline & 21 & 0.4143 & 0.7784 & 0.3374 \\
\hline & 19 & 0.4338 & 0.7794 & 0.2772 \\
\hline & 20 & 0.3702 & 0.7783 & 0.2575 \\
\hline \multirow[t]{4}{*}{ Ar2 } & 20 & 0.4163 & 0.7601 & 0.4673 \\
\hline & 20.9 & 0.4935 & 0.7748 & 0.3093 \\
\hline & 20.5 & 0.4257 & 0.7744 & 0.2856 \\
\hline & 18.5 & 0.4850 & 0.7749 & 0.2686 \\
\hline \multirow[t]{4}{*}{ Ar3 } & 24 & 0.2714 & 0.7696 & 0.5383 \\
\hline & 25 & 0.1860 & 0.7773 & 0.4633 \\
\hline & 25.2 & 0.3192 & 0.7821 & 0.3983 \\
\hline & 23 & 0.3659 & 0.7813 & 0.3852 \\
\hline
\end{tabular}


(Raman data)]which may give rise to unwanted side reactions, thus lowering the net useful current. Further, these defects may act as traps for the $\mathrm{O}_{2}$ and inhibit the diffusion of the reactant and product species thus lowering the catalytic activity.
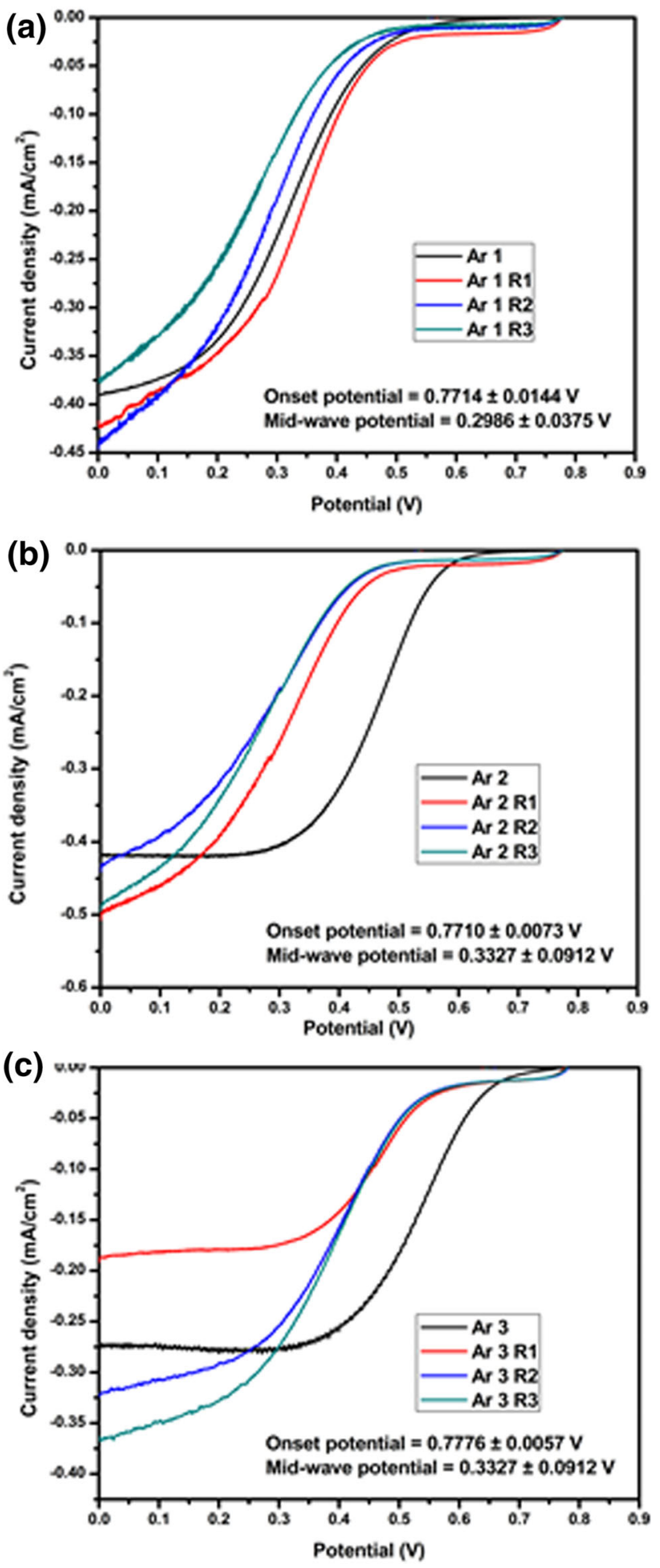

Fig. 7 LSV curves of 4 different electrodes prepared for samples sample a $\mathrm{Ar} 1$, b $\mathrm{Ar} 2$, and c $\mathrm{Ar} 3$ in $\mathrm{O}_{2}$ purged $0.5 \mathrm{M} \mathrm{HClO}_{4}$
From the LSV curves the onset potential and mid-wave potentials were measured. The onset potential gives a potential at which the ORR initiates and was found to be highest for sample Ar3. High activity in terms of onset potential can be attributed to the increase in the electro conductivity of the catalyst [49]; and the increase in the density of the electrochemical active sites due to the enhancement in the surface atoms with a decrease in the particle size and therefore a rise in the probability of early as well as simultaneous reactions, as also stated elsewhere $[50,51]$. High mid-wave potential for Ar3 further reflects low binding energy of the catalyst surface with the reactants which in turn implies fast catalytic activity as the catalyst surface is quickly available for reducing more $\mathrm{O}_{2}$. However, some deviation in the CV and LSV curves and the related parameters have been observed which has been explained later in the text.

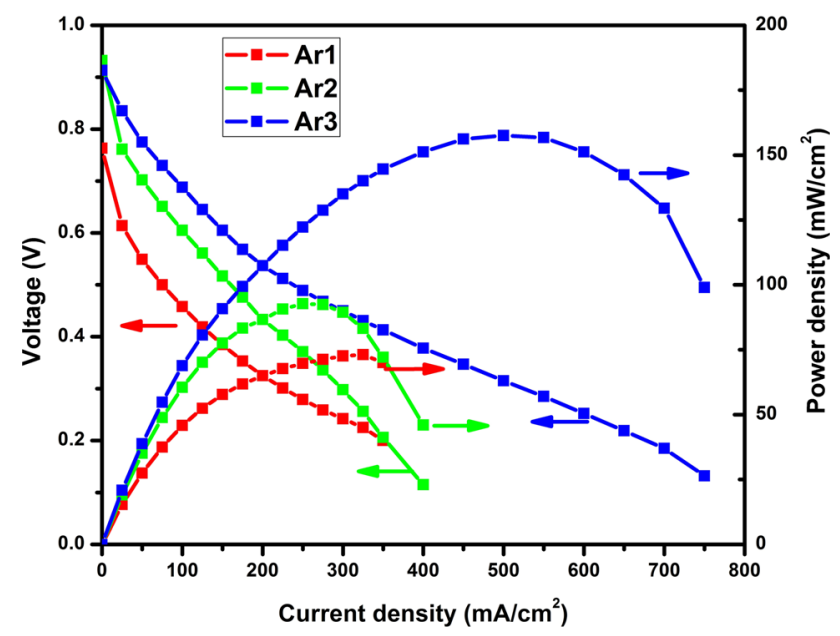

Fig. 8 Polarization curves for catalyst samples Ar1, Ar2, and Ar3

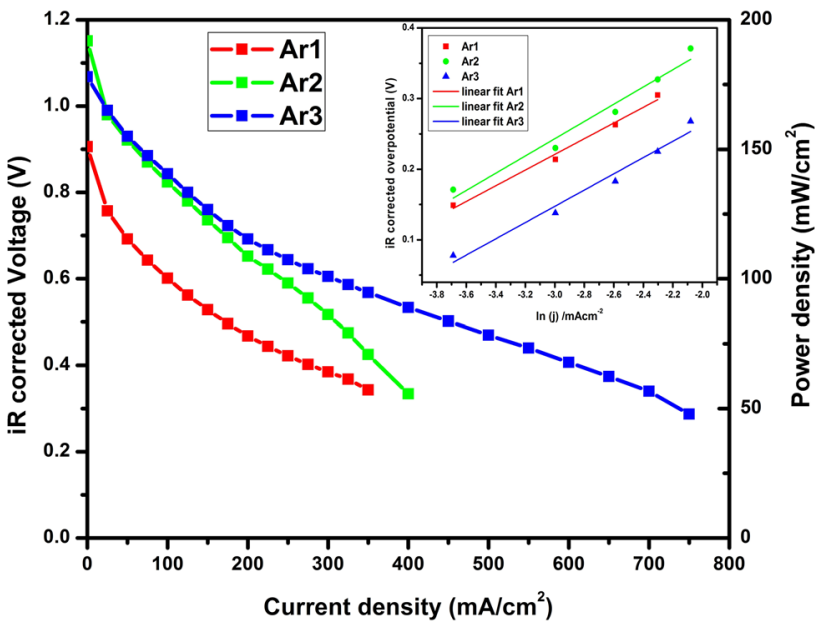

Fig. 9 IR corrected cell polarization curves for the catalyst samples Ar1, Ar2, and Ar3. Inset shows the tafel plots for activation polarization region 
The actual activity of the catalyst is best judged from its fuel cell performance curves. The MEA for catalyst samples was fabricated and tested in single cell. MEA performance is reflected in its polarization curve, a plot of cell voltage versus current density. Figure 8 shows the comparative fuel cell performance with the different catalyst samples. The peak power density achieved while employing Ar1, Ar2, and Ar3 as catalyst was found to be 73, 92, and $156 \mathrm{mWcm}^{-2}$, respectively.
Improved performance of sample Ar3 as compared to Ar1 and Ar2 is probably because of smaller particle size and homogeneous distribution of platinum nano particles.

To calculate the electrode kinetic parameters, the IR corrected cell polarization curves were taken into account as shown in Fig. 9. This helps us to remove the IR contribution coming from the membrane and/or electrolyte so that pure catalyst performance can be evaluated. The tafel plots are shown in the inset while the data are summarized

Table 3 Electrochemical kinetic parameters for the unit PEM fuel cells using catalyst samples Ar1, Ar2, and Ar3

\begin{tabular}{lllll}
\hline Sample & $E_{0}(\mathrm{~V})$ & $j_{0.9}\left(\mathrm{~A} / \mathrm{cm}^{2}\right)$ & $\mathrm{b}(\mathrm{V} / \mathrm{decade})$ & $\alpha$ \\
\hline Ar1 & 0.906 & 1.21 & $0.1220 \pm 0.0121$ & 0.1052 \\
Ar2 & 1.151 & 60.61 & $0.1150 \pm 0.0106$ & 0.1116 \\
Ar3 & 1.068 & 68.15 & $0.1110 \pm 0.0077$ & 0.1156 \\
\hline
\end{tabular}
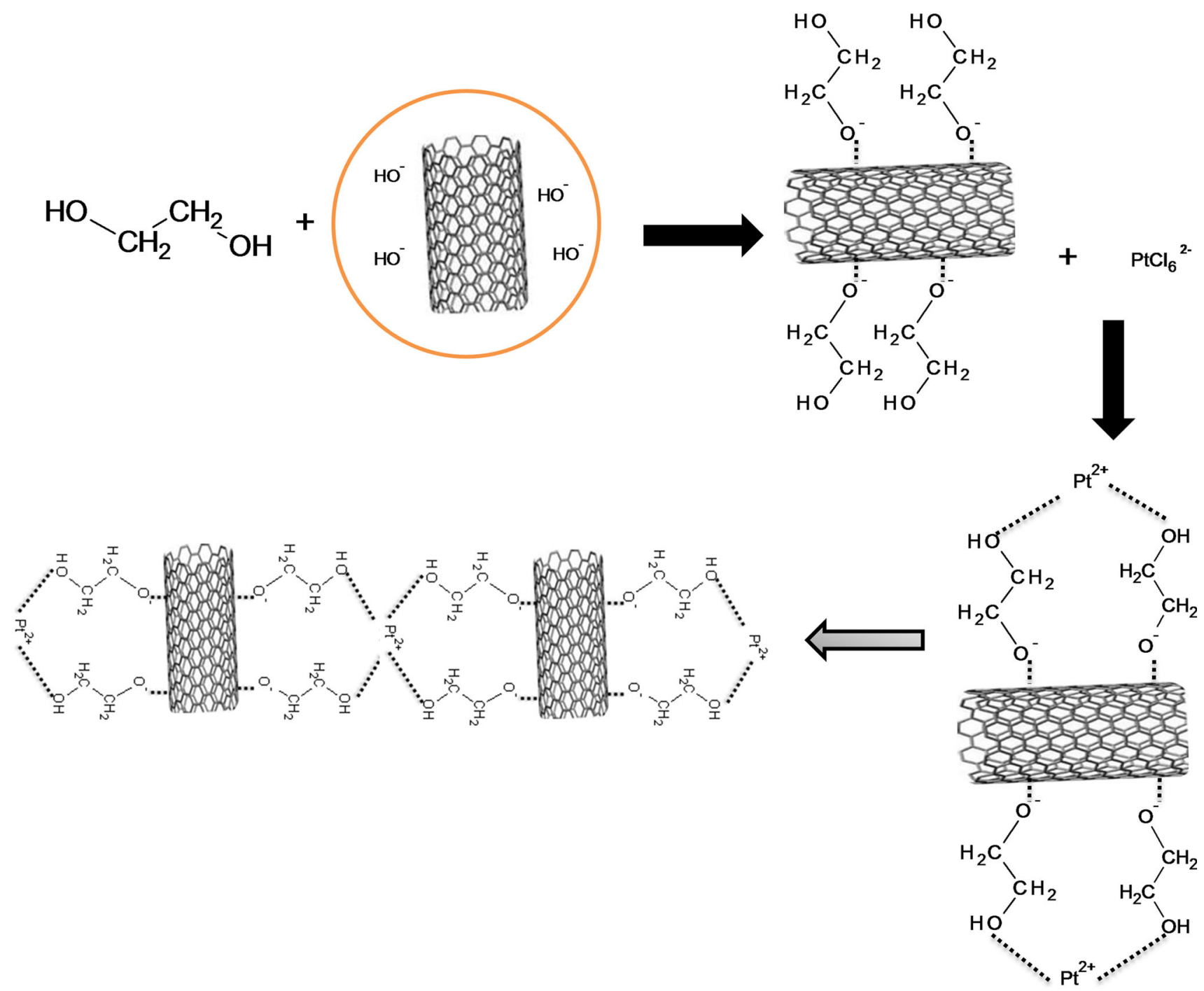

Fig. 10 Detailed reaction mechanism for reaction occurring in basic medium 
in Table 3. The value of $j_{0.9}$ represents the kinetic current density (at the cell potential of $0.9 \mathrm{~V}$ ), while $\alpha$ the charge transfer coefficient is calculated from the slope of the tafel plots. The values of $\alpha$ and $j_{0.9}$ increases for samples Ar1 to Ar3 whereas the tafel slopes of the polarization curves decreases, indicating comparative feasibility of the reaction with sample Ar3. The kinetics of the reaction in alkaline medium can be explained by the following probable reaction mechanism. Addition of $\mathrm{OH}^{-}$ions (increasing basicity) along with EG can catalyze the entire reaction as shown in Fig. 10. This is because $\mathrm{OH}^{-}$ions have the tendency to release protons from $\mathrm{EG}$.

The $\mathrm{OH}-\left(\mathrm{CH}_{2}\right)_{2}-\mathrm{O}^{-}$ion thus produced will bind on the CNT surface for stabilizing its charge. These additional $\mathrm{OH}^{-}$ions will also be available to reduce $\mathrm{Pt}$ which can bind with EG (forming square planar complexes) which is already on CNT surface. Thus, the reaction will become much more feasible as compared to when it is carried out in acidic medium (where it will be difficult to release proton). Further coordinate bonds will be stronger leading to stability of the catalyst formed.

However, when we compare the above results (kinetic parameters) with our previous study when the refluxing was carried out in air [15], a decrease in the catalyst performance is noted in the present case, i.e., when the reaction was carried out in argon. Since refluxing in air has a greater probability of increasing the defects (since air has a number of components along with oxygen) as compared to that in an inert atmosphere like argon, it was assumed that argon refluxing would reduce the formation of defects leading to a smooth and uniform surface, resulting in an enhanced catalytic activity of the synthesized catalyst.

However, our thought was not actualized as there are a number of possibilities while a substance is in the reacting stage. It is important to note that the catalyst performance in a Fuel cell depends on a no. of parameters like the metal (e.g., Pt) used [51-54], metal loading [54-56], type and purity of substrate $[5,57-63]$ etc. Apart from the above another important factor which determines the catalyst performance is the interaction/bond between the metal and substrate. The synthesis/refluxing atmosphere therefore plays a very important role in this regard. It takes part in the reaction by acting as independent specie that stabilizes the excited products formed probably by removing the excess energy and dissipating it in the form of heat.

Argon $\left[3 s^{2}, 3 p^{6}\right]$ with is octet complete probably remains in a non-interactive mode and is therefore unable to carry out the above function of stabilizing the catalyst/nanocomposite. This further explains some non uniformity in the catalyst prepared and the deviation observed in the ex situ electrochemical studies.

\section{Conclusions}

MWCNTs platinum nanocomposites have been synthesized as PEM fuel cell catalyst by reflux heating in argon atmosphere under different $\mathrm{pH}$ conditions. High viscosity of ethylene glycol is effective in stabilizing the diffusion of Pt nanoparticles. The catalytic activity of CNT supported Pt nanoparticles greatly depends on the particle size and distribution and related parameters, which in turn is largely affected by the $\mathrm{pH}$ of the synthesizing medium and the refluxing environment. The $I-V$ performance of unit PEM fuel cell shows a peak power density of $156 \mathrm{~mW} / \mathrm{cm}^{2}$ with catalyst prepared in alkaline medium, which is nearly $110 \%$ more as compared to that obtained while employing catalyst prepared in acidic medium and tested under similar conditions.

Acknowledgments The authors are grateful to Director, NPL, New Delhi for his support, encouragement and permission to publish the results. One of the authors CG wants to thank CSIR-SRF for financial support. Evaluation of the fuel cell performance and technical discussions by the scientists of Central Electrochemical Research Institute (CSIR), Chennai, are gratefully acknowledged. Thanks are also due to Dr. Vidyanand and Singh, Mr. R. K. Seth and Mr. Naval K. Upadhyay for carrying out the TEM, TGA and XRD studies. The studies have been carried out under the CSIR, project entitled "Development of New Generation Energy Efficient Devices (DNEED)".

Open Access This article is distributed under the terms of the Creative Commons Attribution 4.0 International License (http:// creativecommons.org/licenses/by/4.0/), which permits unrestricted use, distribution, and reproduction in any medium, provided you give appropriate credit to the original author(s) and the source, provide a link to the Creative Commons license, and indicate if changes were made.

\section{References}

1. Haile, S.M.: Fuel cell materials and components. Acta Mater. 51(19), 5981-6000 (2003)

2. Park, S., Vohs, J.M., Gorte, R.J.: Direct oxidation of hydrocarbons in a solid-oxide fuel cell. Nature 404(6775), 265-267 (2000)

3. Steele, B.C.H., Heinzel, A.: Materials for fuel-cell technologies. Nature 414(6861), 345-352 (2001)

4. Ilic, D., Holl, K., Birke, P., WÃhrle, T., Birke-Salam, F., Perner, A., et al.: Fuel cells and batteries: Competition or separate paths? J. Power Sources 155(1), 72-76 (2006)

5. Zhang, W., Sherrell, P., Minett, A.I., Razal, J.M., Chen, J.: Carbon nanotube architectures as catalyst supports for proton exchange membrane fuel cells. Energy Environ. Sci. 3(9), 1286-1293 (2010)

6. Shao, Y., Yin, G., Gao, Y., Shi, P.: Durability Study of Ptâ̂• C and Ptâ̂・ CNTs Catalysts under Simulated PEM Fuel Cell Conditions. J. Electrochem. Soc. 153(6), A1093-A1097 (2006)

7. Shao, Y., Yin, G., Zhang, J., Gao, Y.: Comparative investigation of the resistance to electrochemical oxidation of carbon black and carbon nanotubes in aqueous sulfuric acid solution. Electrochimica Acta 51(26), 5853-5857 (2006) 
8. Chen, J., Siegel, J.B., Matsuura, T., Stefanopoulou, A.G.: Carbon corrosion in PEM fuel cell dead-ended anode operations. J. Electrochem. Soc. 158(9), B1164-B1174 (2011)

9. Yousfi-Steiner, N., MoÃßot $\tilde{\complement} \odot$ guy, P., Candusso, D., Hissel, D.: A review on polymer electrolyte membrane fuel cell catalyst degradation and starvation issues: Causes, consequences and diagnostic for mitigation. J. Power Sources 194(1), 130-145 (2009)

10. Cheon, J.Y., Ahn, C., You, D.J., Pak, C., Hur, S.H., Kim, J., et al.: Ordered mesoporous carbon-carbon nanotube nanocomposites as highly conductive and durable cathode catalyst supports for polymer electrolyte fuel cells. J. Mater. Chem. A 1(4), 1270-1283 (2012)

11. Smirnova, A., Dong, X., Hara, H., Vasiliev, A., Sammes, N.: Novel carbon aerogel-supported catalysts for PEM fuel cell application. Int. J. Hydrog. Energy 30(2), 149-158 (2005)

12. Zhang B, Li Juan C, Kai Yong GE, Yan Chuan GUO, Bi Xian P.: Preparation of multiwall carbon nanotubes-supported high loading platinum for vehicular PEMFC application. Chinese Chemical Letters. 16(11), 1531-1534 (2005)

13. Kim, H., Jeong, N.J., Lee, S.J., Song, K.S.: Electrochemical deposition of Pt nanoparticles on CNTs for fuel cell electrode. Korean J. Chem. Eng. 25(3), 443-445 (2008)

14. Jung, D.W., Park, S., Kim, S.H., Kim, J.B., Oh, E.S.: Durability of polymer electrolyte membrane fuel cell with Pt/CNTs catalysts in cell reversal conditions by hydrogen starvation. Fuel Cells. 11(6), 866-874 (2011)

15. Gupta, C., Maheshwari, P.H., Sasikala, S., Mathur, R.B.: Processing of pristine carbon nanotube supported platinum as catalyst for PEM fuel cell. Mater. Renew. Sustain. Energy 3(4), 1-11 (2014)

16. Niu, B., Xu, W., Guo, Z., Zhou, N., Liu, Y., Shi, Z., et al.: Controllable deposition of platinum nanoparticles on single-wall carbon nanohorns as catalyst for direct methanol fuel cells. J. Nanosci. Nanotechnol. 12(9), 7376-7381 (2012)

17. Celorrio, V., Florez-Montano, J., Moliner, R., Pastor, E., Lazaro, M.J.: Fuel cell performance of Pt electrocatalysts supported on carbon nanocoils. Int. J. Hydrog. Energy 39(10), 5371-5377 (2014)

18. Hsin, Y.L., Hwang, K.C., Yeh, C.-T.: Poly (vinylpyrrolidone)modified graphite carbon nanofibers as promising supports for PtRu catalysts in direct methanol fuel cells. J. Am. Chem. Soc. 129(32), 9999-10010 (2007)

19. Popov, V.N.: Carbon nanotubes: properties and application. Mater. Sci. Eng. R Rep. 43(3), 61-102 (2004)

20. Yu, M.-F., Lourie, O., Dyer, M.J., Moloni, K., Kelly, T.F., Ruoff, R.S.: Strength and breaking mechanism of multiwalled carbon nanotubes under tensile load. Science 287(5453), 637-640 (2000)

21. Ruoff, R.S., Tersoff, J., Lorents, D.C., Subramoney, S., Chan, B.: Radial deformation of carbon nanotubes by van der Waals forces. Nature 364(6437), 514-516 (1993)

22. Palaci, I., Fedrigo, S., Brune, H., Klinke, C., Chen, M., Riedo, E.: Radial elasticity of multiwalled carbon nanotubes. Phys. Rev. Lett. 94(17), 175502 (2005)

23. Yu, M.-F., Kowalewski, T., Ruoff, R.S.: Investigation of the radial deformability of individual carbon nanotubes under controlled indentation force. Phys. Rev. Lett. 85(7), 1456-1459 (2000)

24. Minary-Jolandan, M., Yu, M.-F.: Reversible radial deformation up to the complete flattening of carbon nanotubes in nanoindentation. J. Appl. Phys. 103(7), 073516 (2008)

25. Maheshwari, P.H., Gupta, C., Selvaganesh, V., Mathur, R.B.: CNT membrane as a free standing electrode for PEM fuel cell. J. Electrochem. Soc. 161(12), F1146-F1153 (2014)

26. Kannan, A.M., Kanagala, P., Veedu, V.: Development of carbon nanotubes based gas diffusion layers by in situ chemical vapor deposition process for proton exchange membrane fuel cells. J. Power Sources 192(2), 297-303 (2009)

27. Passalacqua, E., Squadrito, G., Lufrano, F., Patti, A., Giorgi, L.: Effects of the diffusion layer characteristics on the performance of polymer electrolyte fuel cell electrodes. J. Appl. Electrochem. 31(4), 449-454 (2001)

28. Tang, Z., Poh, C.K., Tian, Z., Lin, J., Ng, H.Y., Chua, D.H.C.: In situ grown carbon nanotubes on carbon paper as integrated gas diffusion and catalyst layer for proton exchange membrane fuel cells. Electrochimica Acta. 56(11), 4327-4334 (2011)

29. Maheshwari, P.H., Mathur, R.B.: Enhanced performance of PEM fuel cell using MWCNT reinforced carbon paper. RSC Adv. 4(43), 22324-22333 (2014)

30. Hsiao, M.-C., Liao, S.-H., Lin, Y.-F., Weng, C.-C., Tsai, H.M., Ma, C.-C.M., et al.: Polypropylene-grafted multi-walled carbon nanotube reinforced polypropylene composite bipolar plates in polymer electrolyte membrane fuel cells. Energy Environ. Sci. 4(2), 543-550 (2011)

31. Sun, Y.-P., Fu, K., Lin, Y., Huang, W.: Functionalized carbon nanotubes: properties and applications. Access Chem. Res. 35(12), 1096-1104 (2002)

32. Panchakarla, L.S., Govindaraj, A.: Covalent and non-covalent functionalization and solubilization of double-walled carbon nanotubes in nonpolar and aqueous media. J. Chem. Sci. 120(6), 607-611 (2008)

33. Kuzmany, H., Kukovecz, A., Simon, F., Holzweber, M., Kramberger, C., Pichler, T.: Functionalization of carbon nanotubes. Synth. Met. 141(1), 113-122 (2004)

34. Avilés, F., Cauich-Rodríguez, J.V., Moo-Tah, L., May-Pat, A., Vargas-Coronado, R.: Evaluation of mild acid oxidation treatments for MWCNT functionalization. Carbon 47(13), 2970-2975 (2009)

35. Garg, A., Sinnott, S.B.: Effect of chemical functionalization on the mechanical properties of carbon nanotubes. Chem. Phys. Lett. 295(4), 273-278 (1998)

36. Xing, Y.: Synthesis and electrochemical characterization of uniformly dispersed high loading Pt nanoparticles on sonochemically treated carbon nanotubes. J. Phys. Chem. B 108(50), 19255-19259 (2004)

37. Guo, D.J., Li, H.L.: High dispersion and electrocatalytic properties of platinum on functional multi walled carbon nanotubes. Electroanalysis 17(10), 869-872 (2005)

38. Zhang, W., Chen, J., Swiegers, G.F., Ma, Z.-F., Wallace, G.G.: Microwave-assisted synthesis of $\mathrm{Pt} / \mathrm{CNT}$ nanocomposite electrocatalysts for PEM fuel cells. Nanoscale 2(2), 282-286 (2010)

39. Knupp, S.L., Li, W., Paschos, O., Murray, T.M., Snyder, J., Haldar, P.: The effect of experimental parameters on the synthesis of carbon nanotube/nanofiber supported platinum by polyol processing techniques. Carbon 46(10), 1276-1284 (2008)

40. Lee, K., Zhang, J., Wang, H., Wilkinson, D.P.: Progress in the synthesis of carbon nanotube-and nanofiber-supported Pt electrocatalysts for PEM fuel cell catalysis. J. Appl. Electrochem. 36(5), 507-522 (2006)

41. Alexander, L., Klug, H.P.: Determination of crystallite size with the X Ray spectrometer. J. Appl. Phys. 21(2), 137-142 (1950)

42. Spieker, W.A., Liu, J., Miller, J.T., Kropf, A.J., Regalbuto, J.R.: An EXAFS study of the co-ordination chemistry of hydrogen hexachloroplatinate (IV): 1 . Speciation in aqueous solution. Appl. Catal. A 232(1), 219-235 (2002)

43. Chen, X., Chu, W., Wang, L., Wu, Z.: Geometry of Pt(IV) in H 2 $\mathrm{PtCl} 6$ aqueous solution: an X-ray absorption spectroscopic investigation. J. Mol. Struct. 920(1), 40-44 (2009)

44. Fang, B., Chaudhari, N.K., Kim, M.-S., Kim, J.H., Yu, J.-S.: Homogeneous deposition of platinum nanoparticles on carbon black for proton exchange membrane fuel cell. J. Am. Chem. Soc. 131(42), 15330-15338 (2009) 
45. Saito, R., Hofmann, M., Dresselhaus, G., Jorio, A., Dresselhaus, M.S.: Raman spectroscopy of graphene and carbon nanotubes. Adv. Phys. 60(3), 413-550 (2011)

46. Roth, C., Bleith, P., Schwöbel, C., Kaserer, S., Eichler, J.: Importance of fuel cell tests for stability assessment-suitability of titanium diboride as an alternative support material. Energies 7(6), 3642 (2014)

47. Yang, Z., Nakashima, N.: A simple preparation of very high methanol tolerant cathode electrocatalyst for direct methanol fuel cell based on polymer-coated carbon nanotube/platinum. Sci. Rep. 5, 12236 (2015)

48. Wu, J., Yang, H.: Study of the durability of faceted Pt3Ni oxygen-reduction electrocatalysts. Chem. Catal. Chem. 4(10), 1572-1577 (2012)

49. Seo, J., Cha, D., Takanabe, K., Kubota, J., Domen, K.: Particle size dependence on oxygen reduction reaction activity of electrodeposited TaOx catalysts in acidic media. Phys. Chem. Chem. Phys. 16(3), 895-898 (2014)

50. Tang, W., Lin, H., Kleiman-Shwarsctein, A., Stucky, G.D., McFarland, E.W.: Size-dependent activity of gold nanoparticles for oxygen electroreduction in alkaline electrolyte. J. Phys. Chem. C. 112(28), 10515-10519 (2008)

51. Wang, Y.-J., Zhao, N., Fang, B., Li, H., Bi, X.T., Wang, H.: Carbon-supported Pt-based alloy electrocatalysts for the oxygen reduction reaction in polymer electrolyte membrane fuel cells: particle size, shape, and composition manipulation and their impact to activity. Chem. Rev. 115(9), 3433-3467 (2015)

52. Holton, O.T., Stevenson, J.W.: The role of platinum in proton exchange membrane fuel cells. Platin. Met. Rev. 57(4), 259-271 (2013)

53. Zhang, J.: PEM fuel cell electrocatalysts and catalyst layers: fundamentals and applications. Springer, London (2008)

54. Cho, Y.-H., Park, H.-S., Cho, Y.-H., Jung, D.-S., Park, H.-Y., Sung, Y.-E.: Effect of platinum amount in carbon supported platinum catalyst on performance of polymer electrolyte membrane fuel cell. J. Power Sources 172(1), 89-93 (2007)

55. Fofana D, Natarajan SK, BÃ@nard P, Hamelin J.: High Performance PEM Fuel Cell with Low Platinum Loading at the Cathode Using Magnetron Sputter Deposition. ISRN Electrochem. 2013(174834), 1-6 (2013)

56. Zahari NM, Aziz AA.: Effect of platinum catalyst loading on membrane electrode assembly (MEA) in proton exchange membrane fuel cell (PEMFC). Semiconductor Electronics (ICSE), 2012 10th IEEE International Conference on: IEEE; p. 669-73

57. Liu, Z., Gan, L.M., Hong, L., Chen, W., Lee, J.Y.: Carbon-supported $\mathrm{Pt}$ nanoparticles as catalysts for proton exchange membrane fuel cells. J. Power Sources 139(1), 73-78 (2005)

58. Li, W., Liang, C., Zhou, W., Qiu, J., Zhou, Z., Sun, G., et al.: Preparation and characterization of multiwalled carbon nanotubesupported platinum for cathode catalysts of direct methanol fuel cells. J. Phys. Chem. B 107(26), 6292-6299 (2003)

59. Liu, Z., Hong, L., Tay, S.W.: Preparation and characterization of carbon-supported Pt, PtSnO 2 and PtRu nanoparticles for direct methanol fuel cells. Mater. Chem. Phys. 105(2), 222-228 (2007)

60. Andersen, S.M., Borghei, M., Lund, P., Elina, Y.-R., Pasanen, A., Kauppinen, E., et al.: Durability of carbon nanofiber (CNF) \& carbon nanotube $(\mathrm{CNT})$ as catalyst support for proton exchange membrane fuel cells. Solid State Ion. 231, 94-101 (2013)

61. Li, W., Liang, C., Qiu, J., Zhou, W., Han, H., Wei, Z., et al.: Carbon nanotubes as support for cathode catalyst of a direct methanol fuel cell. Carbon 40(5), 791-794 (2002)

62. Sevjidsuren, G., Zils, S., Kaserer, S., Wolz, A., Ettingshausen, F., Dixon, D., et al.: Effect of different support morphologies and pt particle sizes in electrocatalysts for fuel cell applications. J. Nanomater. 2010, 73 (2010)

63. Antolini E.: Carbon supports for low-temperature fuel cell catalysts. Appl Catal B: Environ. 88(1),1-24 (2009) 